\title{
DISCURSO DE LA DIRECTORA DE LA ESCUELA DE DERECHO SRA. LUZ MARÍA REYES SANTELICES
}

Con alegría, con optimismo y con profundo sentido de responsabilidad, queremos compartir hoy con la comunidad de la región de Coquimbo a través de sus más genuinos y destacados representantes que se encuentran presentes en este Salón de Congresos Gabriel González Videla, el enorme desafío que constituye para la Universidad Católica del Norte impartir la tradicional y centenaria carrera de la abogacía.

Estimados amigos de la Escuela de Derecho:

Pronuncié esas palabras en la Ceremonia de Inauguración del Primer año académico de esta Escuela de Derecho, en 1993. Muchos de Uds. estaban allí, preocupados, incrédulos y hasta desconcertados.

¿Una Escuela de Derecho en nuestra región? ¿Qué es eso de una Escuela universitaria para formar futuros abogados? ¿Cuál será su dirección y su destino? ¿quienes serán sus profesores, quiénes sus alumnos? ¿Un desprestigio para la profesión de abogado? ¿O tal vez una buena oportunidad para los jóvenes de esta zona?

Preguntas difíciles de responder. Sólo contábamos a la sazón con la decisión firme de las autoridades de la Universidad Católica del Norte, de cumplir con su misión de estar al servicio del desarrollo del hombre y de todos los hombres de nuestro pueblo.

Y también, con el inapreciable apoyo de la Facultad de Derecho de la Pontificia Universidad Católica de Chile y de un grupo de destacados juristas de la región, que decididamente conformaron un consejo asesor de la Dirección. Comprometer a los abogados de la zona para que se incorporaran a las actividades docentes no era fácil. Hasta hace poco más de un lustro, pensar en una Escuela de Derecho en esta región era un sueño. Sólo oir hablar del tema provocaba severas reacciones adversas y muchas voces se alzaban airadas terminando o postergando cualquier proyecto académico en este sentido.

Pero teníamos a marzo de 1993 un grupo de 65 alumnos, inteligentes y resueltos a estudiar derecho en nuestra Universidad y no los podíamos defraudar. Debían iniciarse las clases y ese año, en las asignaturas de formación general contamos con la destacada participación de académicos del Departamento de Teología de la Universidad, cuyo aporte inicial resultó inapreciable. Y comprometimos a algunos abogados y a un profesor de castellano, quienes creyeron en nuestro proyecto y se involucraron en él, convirtiéndose junto con los primeros alumnos, en pilares fundamentales de esta Escuela de Derecho.

Nos sorprendió la creación de nuestra Escuela, en un proceso de cambios científico-técnicos, comunicacionales, políticos-económicos y socio-culturales- que la modernidad ha introducido en el mundo y en nuestro país, los que no podemos desconocer como universidad. Eso torna a la tarea emprendida más compleja, ya que la enseñanza del derecho debe adecuarse a la turbadora mutación que experimentamos en estos tiempos veloces y competitivos. 
El desafío es grandioso, y por lo mismo tremendamente motivador. Sólo las metas realmente ambiciosas tienen seguidores y fructifican.

Durante estos cinco años, hemos intentado ir delineando lo que debe ser una Escuela de Derecho en una Universidad Católica, regional y tradicional, que se distinga, que irradie, y que salvaguarde el cultivo de las humanidades, tan caras al cristianismo y en ocasiones tan menospreciado. $Y$ hemos pensado que eso se logra cuando la Universidad influye sobre el mundo y no al revés.

Los principales objetivos trazados al inicio de la carrera fundamentalmente se referían a lograr la excelencia docente y la atención personalizada, afectuosa pero a la vez firme de nuestros alumnos, por una parte, y por la otra, a la conveniencia de situar a la Escuela de Derecho en un lugar de privilegio entre sus pares y frente a la sociedad en que se encuentra inserta.

No obstante las dificultades propias de una carrera en desarrollo inicial y las que siempre se deben enfrentar en regiones cuando se persiguen metas superiores, nuestra Escuela tiene hoy un nombre y se alza como un proyecto académico serio y responsable, en vías de una temprana consolidación.

Debo reconocer la sostenida disposición de las autoridades de la Universidad Católica del Norte, y principalmente de su Rector don Juan Andrés Music, para comprender las implicancias de la creación de una Escuela de Derecho, por tradición diferente a otras carreras universitarias. Asimismo, el trabajo siempre armónico con el Vicerrector y las autoridades y funcionarios no académicos de la sede, nos ha permitido llevar adelante en la mejor forma nuestro proyecto .

Al culminar con éxito esta primera etapa de la carrera, es preciso prepararse para enfrentar nuevos desafíos y reflexionar fundamentalmente en torno a su futuro devenir. que tal vez nos resulte más escarpado y para ello, el renovado esfuerzo de profesores y alumnos será fundamental. No podemos perder de vista que la Universidad debiera siempre y en cada una de sus disciplinas- tanto enseñar a pensar cuanto fundarse en el estudio y la investigación. Los profesores de esta Escuela de Derecho, debemos enseñar a pensar a los estudiantes y esto sólo puede hacerse pensando ante ellos, con ellos. Y ellos por su parte, han de tener una mente abierta y receptiva, ya que nada pueden hacer los maestros si no cuentan con estudiantes con verdadera vocación de universitarios.

Esperamos de cada uno de nuestros docentes que sean ante todo, discentes, alguien que busca ampliar, mejorar y discernir el horizonte de su saber. $Y$ para ello, en la Universidad tienen que haber las mínimas condiciones para la existencia y el desarrollo del estudio y la investigación: por un lado, la Escuela deberá tener un grupo de personas con jornada completa, idóneas, bien formadas, a nivel de posgrado, por supuesto, con tiempo y tranquilidad económica para el estudio y el descubrimiento, y por el otro, medios materiales adecuados y suficientes, sobre todo biblioteca y el tan indispensable espacio físico, para trabajar dignamente.

Esta Escuela pertenece a una Universidad Católica.

No podemos por tanto eludir la responsabilidad de asumir con entusiasmo y decisión, la consecución de una integración del saber en que tenga un lugar de privilegio el diálogo entre fe y razón y una preocupación por la formación ética de nuestros alumnos, 
día a día, clase a clase, sustentada en el ejemplo de sus profesores, más allá de toda neutralidad valórica.

Anhelamos contribuir a que esta Casa de Estudios sea cada vez más y mejor una Universidad Católica y Humanista. Sólo en ella nuestra Escuela de Derecho podrá dar sus mejores frutos, procurando siempre el mérito y la excelencia en todas sus actividades y optando decididamente por estudiar, investigar, enseñar y difundir a partir de la tradición ética y jurídica que remonta de judíos, griegos, romanos y cristianos. Ello exigirá la colaboración de todos sus integrantes: autoridades, profesores, alumnos y funcionarios. La práctica sencilla y anónima de la virtud, la solidaridad efectiva y silenciosa, el compromiso con una educación superior que informe, forme e incluso reforme, la apertura universal y la tolerancia, un espíritu familiar y una comunidad de destinos: tales son algunas de las condiciones para que nuestra Escuela, como parte de la Universidad Católica del Norte, logre obtener sus más caros anhelos.

Son muchas las personas que durante estos cinco años han venido haciendo Universidad en esta Escuela de Derecho. Permítanme dirigirles a ellos unas palabras.

A quienes hoy egresan:

Rafael, Tatiana, Carlos, Marcia, Jenny, Cristian, Esteban, Claudia, José Luis, Irene, Elisa, María Carolina, Marcial y Alejandro, quiero que me escuchen:

Los recibí en marzo de 1993, cuando iniciaban su vida universitaria sumándose a mi propia incertidumbre respecto a lo que sería esta Escuela de Derecho. Fui su profesora en segundo año, y recuerdo haber intentado transmitirles valores como la dignidad de la persona humana, su libertad, y el respeto por sus derechos emanados de su propia naturaleza. Después, he seguido desde una discreta distancia el avance de cada una de Uds., me he alegrado con sus éxitos, he sufrido con sus frustraciones estudiantiles y personales. He tratado de tener siempre en consideración que para Uds. el ser la primera promoción de nuestra Escuela de Derecho, ha constituido y constituye una gran responsabilidad, que han sabido asumir con madurez y entereza y por ello les estoy profundamente agradecida. Los animo a cultivar con entusiasmo lo que muy bien comprendieron en marzo de 1993: realizar bien el trabajo diario, con alegría, con creatividad, con entrega personal, privilegiando siempre el ser por sobre el tener, ya que sólo así podremos prestigiarnos como personas y como profesionales.

Por último, mis queridos ex alumnos, los invito a luchar incansablemente, sin claudicaciones ni declinaciones en el transcurso del tiempo, por aquel ideal de justicia que debe ser siempre el faro luminoso que oriente nuestro andar, cualquiera ser el camino que hayamos elegido.

A los profesores de esta Escuela, que con esfuerzo y generosidad han permitido que las actividades docentes se realicen adecuadamente, los invito a compartir nuestro contentamiento por los resultados obtenidos y les expreso mi más sincero agradecimiento. Mis queridos amigos: he sentido el apoyo y la amistad de todos Uds. para llevar adelante la compleja misión que la Universidad Católica del Norte ha puesto en nuestras manos, he sabido de muchas tardes de domingo y de sábados también, dedicadas por Uds. al mejor cumplimiento de las actividades docentes.

Estoy plenamente conciente que en ocasiones la carga se torna insostenible y que nos parece que hay pocos incentivos para un desafío profesional que nos ha resul- 
Revista de Derecho - Universidad Católica del Norte - Sede Coquimbo - 1998

tado más complejo de lo que nunca imaginamos. Pero no podemos perder de vista que lo que está en juego es mucho: debemos formar hombres y mujeres de derecho y de bien, por el engrandecimiento de nuestra patria y por el prestigio de nuestra profesión. Y no es tarea fácil ; para ello debemos permanecer estrechamente unidos en nuestro ideal, mirando tan sólo ese gran objetivo, dejando de lado todo agotamiento y cualquier desazón. $Y$ eso cuesta, y a veces cuesta mucho, pero a todos Dios nos ha dado una privilegiada inclinación a la vida universitaria que debe permitirnos decir $\mathrm{SI}$, y seguir adelante, con más alegría, con mucho optimismo, y con un sentido de responsabilidad acrecentado por la valiosa experiencia de estos maravillosos cinco años de nuestras vidas. 